\section{arquivos analíticos de políticas educativas}

Revista acadêmica, avaliada por pares, independente, de acesso aberto, e multilíngüe

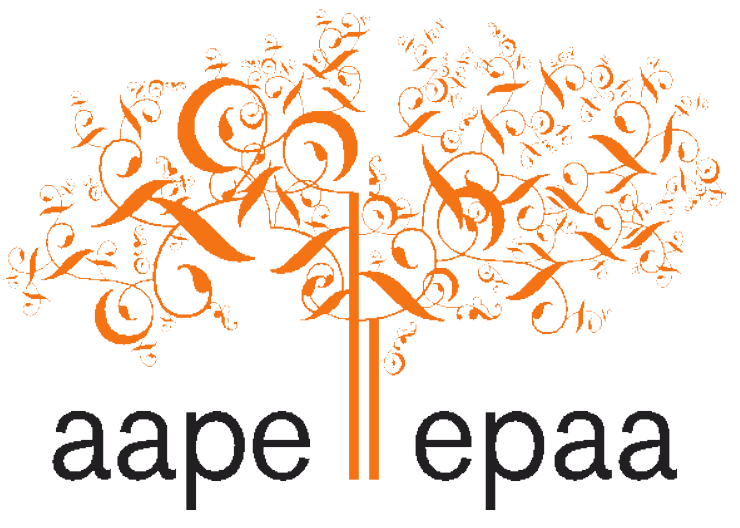

Arizona State University

Volume 26 Número 112

17 de setembro de 2018

ISSN 1068-2341

\title{
Tecnologias Educacionais como Ferramentas: Considerações Críticas Acerca de uma Metáfora Fundamental
}

\author{
Giselle Martins dos Santos Ferreira \\ PUC-Rio \\ $\&$ \\ Márcio Silveira Lemgruber \\ PPGE/UNESA \\ Brasil
}

Citação: Ferreira, G. M. S., \& Lemgruber, M. S. (2018). Tecnologias educacionais como ferramentas: Considerações críticas acerca de uma metáfora fundamental. Arquivos Analíticos de Politicas Educativas, 26(112). http://dx.doi.org/10.14507/epaa.26.3864 Este artigo faz parte do dossiê especial, Edtech e Políticas de Formação Humana, editada por Lílian do Valle, Daniel Mill e Aldo Victorio Filho.

Resumo: No Plano Nacional de Educação vigente (2014-2024), a palavra tecnologia aparece repetidamente na descrição de estratégias propostas para apoiar as metas definidas no documento. Ainda que o termo ferramenta não figure explicitamente no texto, sugere-se a ideia da tecnologia como ferramenta que é amplamente disseminada nos discursos acadêmicos e de marketing da tecnologia educacional. Trata-se de uma metáfora fundamental (Perelman \& TytecaOlbrecht) ou conceptual (Lakoff \& Johnson), ou seja, uma metáfora que encapsula determinadas 
formas de perceber, pensar e relacionar-se com o mundo, e, assim, estrutura o pensamento e a ação. Este artigo discute a metáfora da tecnologia como ferramenta como uma concepção insidiosa e duplamente perigosa, pois, ao oferecer suporte à visão da tecnologia como neutra, expressa na perspectiva de que os impactos de determinados artefatos são função apenas de seus usos, reflete uma perspectiva reducionista da relação entre o humano e o técnico. O texto discute o modo como essa metáfora apoia formas de conceber a tecnologia que precisam ser examinadas, pois a visão simplista e acrítica que promove tende a obscurecer questões fundamentais relativas à multiplicidade de contextos de produção e consumo de artefatos criados por uma indústria com pautas e interesses primordialmente comerciais.

Palavras-chave: Tecnologia Educacional; Retórica; Políticas Educacionait

Educational technologies as tools: Critical considerations on a fundamental metaphor Abstract: In the current National Education Plan (2014-2024), the word technology appears repeatedly in the description of strategies proposed to support the goals defined in the document. Although the term tool is not explicitly included in the text, the idea of technology as tool is widely disseminated in academic and marketing discourses on educational technology. This image can be viewed as a fundamental (Perelman \& Tyteca-Olbrecht) or conceptual (Lakoff \& Johnson) metaphor, that is, a metaphor that encapsulates certain ways of perceiving, thinking and relating to the world, and, thus, structures thought and action. This article discusses the metaphor of technology as tool as an insidious and doubly dangerous conception since, whilst it supports a view of technology as neutral, expressed in a perspective on the impacts of certain artefacts as depending only on their uses, the metaphor reflects a reductionist perspective on the relationship between human and technical. The text discusses the ways in which this metaphor supports conceptions of technology that need to be examined, as the simplistic and uncritical view it promotes tends to obscure fundamental questions regarding the multiple contexts of production and consumption of artefacts created by an industry with agendas and interests that are primarily commercial.

Keywords: Educational Technology; Rhetoric; Educational Policy

\section{Tecnologías educativas como herramientas: Consideraciones críticas acerca de una metáfora fundamental}

Resumen: En el Plan Nacional de Educación vigente (2014-2024), la palabra tecnología aparece repetidamente en la descripción de estrategias propuestas para apoyar las metas definidas en el documento. Aunque el término berramienta no figura explícitamente en el texto, se sugiere la idea de la tecnología como herramienta que es ampliamente diseminada en los discursos académicos y de marketing de la tecnología educativa. Se trata de una metáfora fundamental (Perelman \& TytecaOlbrecht) o conceptual (Lakoff \& Johnson), es decir, una metáfora que encapsula ciertas formas de percibir, pensar y relacionarse con el mundo, y así estructurar el pensamiento y la acción. Este artículo discute la metáfora de la tecnología como herramienta como una concepción insidiosa y doblemente peligrosa, pues, al brindar soporte a la visión de la tecnología como neutra, expresada en la perspectiva de que los impactos de determinados artefactos son función sólo de sus usos, refleja una perspectiva reduccionista de la relación entre lo humano y el técnico. El texto discute la forma en que esta metáfora apoya formas de concebir la tecnología que necesitan ser examinadas, pues la visión simplista y acrítica que promueve tiende a oscurecer cuestiones fundamentales relativas a la multiplicidad de contextos de producción y consumo de artefactos creados por una industria con pautas e intereses primordialmente comerciales.

Palabras-clave: Tecnología Educativa; Retórica; Políticas Educativas 


\section{Introdução}

As discussões sobre a relação entre a educação e a tecnologia - na literatura acadêmica, nos discursos de marketing, na linguagem jornalística - mobilizam, com frequência, a imagem da tecnologia como ferramenta, ou seja, de tecnologias como artefatos neutros que simplesmente cumprem determinadas funções em tarefas conduzidas por quem delas faz uso. Lamentavelmente, muito do que se diz sobre a tecnologia na educação, mesmo na literatura acadêmica, tende a adotar perspectivas apolíticas e descontextualizadas da técnica e, assim, carecendo de historicidade, carecem, também, em muitos casos, de relevância à multiplicidade de práticas educativas concretizadas em cotidianos de diferença e de desigualdade (Rosado, Ferreira \& Carvalho, 2017). Porém, em uma contemporaneidade marcada, de forma geral, pela rápida expansão da base tecnológica digital em todos os setores de atividades humanas, imagens e concepções da tecnologia circulam, inclusive, nas formas que toma o senso-comum ao tratar de questões da educação. Circulam, também, e com implicações potencialmente abrangentes, nos discursos que constroem as políticas públicas na área.

No Plano Nacional de Educação vigente (PNE 2014-2024), a palavra tecnologia aparece repetidamente na descrição de estratégias propostas para apoiar as várias metas definidas no documento. Formas adjetivadas tais como tecnologias assistivas, tecnologias educacionais e tecnologias pedagógicas figuram como elementos centrais de estratégias relativas a metas de alfabetização, ampliação do acesso à educação e formação profissional em diferentes níveis, incluindo a Educação Superior. Softwares, plataformas, salas multifuncionais, Recursos Educacionais Abertos, dentre outros rótulos da tecnologia educacional (Selwyn, 2015), são propostos como meios para que se atinja determinados objetivos. Apesar de sugerir uma distinção entre tecnologia (área do conhecimento) e sua forma pluralizada (artefatos), o documento veicula, de forma ampla, uma perspectiva simplista de artefatos tecnológicos como "ferramentas".

Trata-se, de fato, de uma metáfora fundamental (Perelman \& Olbrecths-Tyteca, 1996) ou conceptual (Lakoff \& Johnson, 2002), ou seja, uma metáfora que encapsula determinadas formas de perceber, pensar e relacionar-se com o mundo, e, assim, estrutura o pensamento e a ação. Este artigo sugere que tal metáfora encapsula uma concepção insidiosa e duplamente perigosa, pois, ao oferecer suporte à visão da tecnologia como neutra, fundamental à ideia de que os "impactos" de determinados artefatos são função apenas de seus usos, promove uma perspectiva reducionista da relação entre o humano e o técnico. O texto discute o modo como essa metáfora apoia formas de conceber a tecnologia que precisam ser examinadas, pois a visão acrítica que promove tende a obscurecer questões fundamentais relativas à multiplicidade de contextos de produção e consumo de artefatos criados por uma indústria com pautas e interesses primordialmente comerciais.

\section{A Metáfora Amputada e sua Revalorização}

Podemos dizer que as metáforas e a retórica - tradição que muito as valorizou - não tiveram vida fácil na história do pensamento ocidental. Ainda na Grécia Antiga, estabeleceu-se uma tensão que iria perpassar muitos séculos, existindo até hoje. Como não poderia deixar de ser, seus dois grandes representantes são Platão e Aristóteles. Para o primeiro, ao defender uma concepção essencialista do conhecimento, a arte (aí a poesia e as metáforas) e a retórica eram vistas com desconfiança, pois estimulariam tão somente as emoções e afastariam os homens da verdade real. Aristóteles, por outro lado, defendia que as metáforas não eram meros ornamentos, mas uma forma de conhecimento. Umberto Eco, em seu livro póstumo (2017, p. 328), assim se expressou a esse respeito: 
$\mathrm{Na}$ Poética, ele diz que entender as boas metáforas significa "saber discernir o semelhante ou o conceito afim". O verbo que usava era theorein, que vale por discernir, investigar, comparar, julgar. Mas Aristóteles retornou com mais delonga a esta função cognitiva da metáfora na Retórica, em que dizia que é agradável aquilo que suscita admiração porque nos faz descobrir uma analogia insuspeita, ou seja, "coloca debaixo de nossos olhos" (assim se exprimia ele) algo que nunca tínhamos notado, de modo que somos levados a dizer "veja, é isso mesmo, e eu não sabia”.

Como se pode ver, Aristóteles designava assim uma função quase científica às boas metáforas, mesmo que se tratasse de uma ciência que não consistia em descobrir uma coisa que já estava lá, mas antes, por assim dizer, em fazê-la aparecer ali pela primeira vez, em criar um modo de olhar as coisas.

Ainda que na civilização romana a retórica tivesse grande prestígio, com Cícero e Quintiliano a concebendo como a arte do bem falar indissociável do bem argumentar, ao longo dos séculos ela foi perdendo sua verve argumentativa, reduzindo-se a artifícios de oratória ou estilística. Aliás, geralmente, com gosto duvidoso diante do exagero de chavões. Assim é que, no século XVI, Rabelais (2009) ironizou a educação calcada na leitura e memorização de uma infinidade obras, ao longo de muitos anos: "Gargântua saiu tão sábio quanto já era antes" (p. 79). Igualmente, Michel de Montaigne, nos Ensaios (1996), onde usou e abusou das metáforas e analogias na construção de suas argumentações, execrou as aulas de retórica, classificando-as como inúteis, não estimulando o desenvolvimento do pensamento do aluno. Criticou que elas formavam "cabeças de pote", que só sabiam decorar as lições: Não cansou de manifestar desprezo pela prolixidade, maneirismo, pelo esbanjamento de fórmulas servis: "Abaixo a eloquência que atrai a nossa atenção para ela mesma e não para seus temas.” (Montaigne, 1996, p. 231).

Chaïm Perelman (1999, p. 23) apontou que, em 1555, Pierre Ramus (Dialectique) sacramentara a condenação da retórica, ao classificar no trivium - artes do discurso - "a dialética como a arte de bem raciocinar e a retórica como a arte do bem dizer, isto é, do uso eloquente e ornamentado da linguagem", inaugurando uma linhagem que a limitaria ao estudo das figuras de linguagem.

Deste modo, apesar de a concepção de Aristóteles sobre as metáforas contemplá-las também como recursos cognitivos, tal entendimento não vingou como hegemônico no pensamento filosófico da modernidade. Como ilustração da desvalorização das metáforas, trazemos as citações de Hobbes e Locke, elencadas na seção sugestivamente intitulada "Medo da metáfora" de Lakoff e Johnson (2002). No Leviatã, Hobbes afirmou que "raciocinar com base nelas é perder-se entre absurdos inumeráveis" e censurou "o uso da metáfora, dos tropos e de outras figuras de retórica em lugar das palavras no sentido próprio... tais maneiras de falar não devem ser admitidas no cálculo e na busca da verdade." (conforme citado em Lakoff \& Johnson, 2002, p. 300). Por seu turno, Locke, no Ensaio acerca do entendimento bumano, vai além, e não deixa pedra sobre pedra na condenação das metáforas e da retórica:

... se quisermos falar das coisas como elas são, devemos reconhecer que toda a arte da retórica, além da ordem e da clareza, toda a aplicação artificial e figurada das palavras que as regras da eloquência inventaram, não servem senão para insinuar ideias erradas no espírito, para mover paixões e, por meio disso, perturbar o julgamento; e, então, são de fato fraudes perfeitas; e, portanto, embora a oratória laudatória e permissível possa torná-los arengas e discursos dirigidos ao povo, indubitavelmente, é preciso evitá-las por completo em todos os discursos que pretendem informar ou instruir; e em que a verdade e o conhecimento estão em questão, não se pode pensar que sejam outra coisa a não 
ser um grande defeito ou da língua ou da pessoa que as utiliza... É evidente os homens amam enganar e ser enganados, uma vez que a retórica, esse instrumento poderoso do erro e do engano, tem seus professores estabelecidos é ensinada publicamente e sempre teve grande reputação. (Locke, conforme citado em Lakoff \& Johnson, 2002, p. 300)

Nesse contexto, as metáforas passaram a ser vistas como um expediente válido para a poesia e literatura, mas que deveria ser evitado pelo pensamento sério, seja filosófico ou científico. É o que Max Black apontou - e a que se contrapôs - como um dos mandamentos da filosofia: "não cometerás metáfora", e ironizou: "dar atenção às metáforas de um filósofo é diminuí-lo - é algo como elogiar um lógico por sua caligrafia formosa” (Black, 1966, p. 36).

Além de Modelos e Metáforas de Max Black, outras obras foram marcantes, no século XX, para o resgate do papel cognitivo das metáforas, como A Metáfora Viva, de Paul Ricoeur (2005/1975). Cabe destacar a importância de uma obra fundamental, que sequer foi traduzida entre nós. Philosophy of Rhetoric, publicada em 1936, de Ivor Armstrong Richard é um marco na revitalização da retórica e das metáforas.

No presente artigo, dialogamos, sobretudo, com as ideias expressas no Tratado da Argumentação: a nova retórica (1996/1956) de Chaïm Perelman e Lucie Olbrechts-Tyteca (e outras obras de Perelman), e em Metáforas da Vida Cotidiana, de George Lakoff e Mark Johnson (2002/1980).

\section{Metáforas Fundamentais e Conceituais}

Metáforas apontam para deslocamentos de significado. São tropos, isto é, figuras de linguagem que permitem dizer uma coisa no lugar de outra. Ficam evidentes na linguagem poética, por exemplo, ao se comparar o brilho dos olhos da pessoa amada ao das estrelas. Mas, nas conversas do dia-a-dia, frequentemente, passam imperceptíveis. Assim, quando pedimos: "por favor, passe-me aquela folha de papel que deixei no braço da cadeira", recorremos a deslocamentos de significados, pois, originalmente, folhas dizem respeito a plantas e braços a pessoas. Tais expressões, quando se tornam a maneira habitual - se não inevitável - de nos referirmos a algo, como que se desmetaforizam pelo uso. São, por isso, chamadas de metáforas mortas ou adormecidas.

Segundo a teoria da argumentação de Chaïm Perelman (1987, 1996, 1997, 1999), o estudo da metáfora é inseparável da analogia. A metáfora é tomada como uma analogia condensada. O autor recorreu a Aristóteles, para nos trazer uma ilustração de sua concepção. Pode-se qualificar alguém de velho, ao se afirmar que está "na noite da vida". Tal metáfora condensa a analogia que lhe subjaz: "a velhice está para a vida assim como a noite está para o dia”. Nessa ilustração, a vida é o tema que vai ser qualificado com elementos do foro (o dia). Diversamente, aquilo que a analogia explica, explicitando a similitude de relações, a metáfora condensa, numa expressão. Por isso, a metáfora é impactante, própria da linguagem literária, da poesia, enquanto a analogia, explicativa, presta-se melhor como recurso didático.

Fica evidente que a similitude de relações existentes nas analogias ("a velhice está para a vida, assim como a noite está para o dia”) tem um parentesco com as proporções matemáticas (3 está para 9, assim como 5 está para 15). Contudo, a grande diferença é que, ao contrário desta, analogias não apresentam uma igualdade de relações: seus termos não são intercambiáveis, não são dedutíveis como a incógnita de um dos termos da proporção matemática. Nesse sentido, é fundamental se ter em conta que analogias (e metáforas) dizem respeito a similitudes - e não, igualdades de relações. Por aproximar termos que não são da mesma natureza, analogias e metáforas não dizem respeito ao falso ou verdadeiro, isto é, não têm gabarito. O que vale é a sua eficiência em passar uma ideia, em suscitar a invenção. Por essa razão, pagam o preço pela aproximação de campos diversos. Ao destacar pontos 
que são pertinentes à visão que pretende defender, restam aspectos que são postos de lado, como, recorrendo a um exemplo de Max Black (1966), tomar-se uma batalha como um jogo de xadrez, omitindo-se o elemento humano e suas consequências. Conforme enfatizamos em outro texto (Lemgruber \& Ferreira, 2018),

Essa é uma limitação tanto na argumentação em geral - o interlocutor pode trazer à cena esses aspectos que escapam ou contradizem - como no ensino, onde, depois de dar um patamar inicial, podem prejudicar uma compreensão mais complexa. É o caso da analogia do átomo com o sistema solar, que dá um chão para alunos iniciantes em Física, mas que se tornará um obstáculo epistemológico para quem se aprofundar nessa ciência. Por isso, deveriam ser concebidas como analogias andaime, retiradas (superadas) depois de fornecerem uma compreensão inicial.

É sugestivo o título de um dos mais importantes livros sobre metáforas, publicado nos anos 1980, por George Lakoff e Mark Johnson: Metaphors we live by. Seu título, entre nós, ficou Metáforas da vida cotidiana (2002). Porém, Metáforas pelas quais vivemos dá melhor a ideia de que nos constituem, na medida em que nossas percepções são por elas balizadas.

Metáforas apresentam aspectos de instabilidade, possibilitando que o interlocutor as prolongue de uma forma não prevista. Diante do consenso de que luz representa positividade e trevas negatividade, pode-se destacar que o excesso de luminosidade também cega, ofuscando a visão.

Entretanto, para além dessa fragilidade - por não imporem uma adesão necessária, o que seria característica da razão demonstrativa e não da argumentativa - a força de certas metáforas vem do fato que sua aceitação impõe como que um conjunto de conclusões, um elenco de metáforas que lhes são subordinadas e coerentes. Essas metáforas que balizam e estruturam a visão de um campo são chamadas, na teoria da argumentação, de metáforas fundamentais. Cumprem uma função semelhante a das metáforas raiz de Black (1966) ou das metáforas conceituais de Lakoff e Johnson (2002). Segundo Perelman, Quando a analogia não preenche senão um papel heurístico, não há lugar para se interrogar se a analogia é verdadeira ou falsa. Aquilo que importa é a sua utilidade como hipótese de trabalho, modelo provisório. Mas o papel da analogia é muito diferente nos domínios que escapam ao controle da experiência, e em que se trata de estruturar um domínio da realidade, de sugerir uma nova visão das coisas, fundamento de uma concepção filosófica ou teológica. É neste contexto que se pode falar de metáforas fundamentais, root metaphors. Que pretendem impor como verdadeira uma ontologia, uma visão de mundo. Todo o raciocínio filosófico ou teológico, em lugar de se iniciar por uma metáfora que no fim deve ser eliminada, tentará apresentar as razões que vão justificar a preferência conferida, em última análise, a determinada analogia em detrimento de outra. É nesse contexto que se deverá falar de "verdade metafórica", aquela que exprime o real de maneira mais adequada. (Perelman, 1987, pp. 209-210)

A seguir, apresentamos algumas metáforas que cumprem esse papel em relação ao conhecimento e à prática educacional. 


\section{Metáforas Fundamentais do Conhecimento e da Educação}

Nossa percepção do mundo, além das limitações impostas pelos filtros biológicos (espectros de sons, cores, partículas, que captamos), é balizada por filtros culturais. Precisamos de óculos sociais para transitar pelo real (amálgama de manchas) e domesticá-lo enquanto realidade fabricada. $\mathrm{E}$ as metáforas são um dos principais elementos dessa construção social da realidade. Muitas delas são tomadas do mundo sensível e, pelo uso, se naturalizam. Assim, quase não as percebemos como tal. Quando dizemos que um pensamento é claro, profundo, superior, pleno ou, ao contrário, obscuro, raso, inferior, vaziio, estamos usando como adjetivações positivas ou negativas elementos do meio físico que, em si, não têm tal carga valorativa. O problema não está em sua utilização, mas, sim, em sua naturalização, em não percebê-las como construções sociais e que, por isso, carregam ambiguidades. Por exemplo, o par claro vs. escuro atravessa a história da filosofia, desde o mito da caverna de Platão (sol vs. sombra) ao Século das Luzes (Iluminismo). Ao contrário, a Idade Média seria um período de trevas, e Heráclito, o obscuro. O sentido unívoco de tais valorizações e desvalorizações pode, contudo, ser desequilibrado se desenvolvemos a metáfora, trazendo aspectos negativos da clareza, ao apontar que o excesso de luz ofusca a visão.

Outros pares de metáforas orientacionais também provêm do meio físico e são naturalizadas ao balizar nossas percepções:

Dentro vs. fora - Positividade: central, centralidade, inclusão. Negatividade: periférico, marginal, exclusão.

Em cima vs. em baixo - Positividade: superior, alto, ápice, topo. Negatividade: inferior, baixo, subalterno.

Há, no entanto, a possibilidade de outras matrizes de percepções, em culturas diversas. É o que relatos de antropólogos frequentemente nos trazem. Também a arte pode abalar modos de ver o mundo. Já se disse que, enquanto os discursos filosóficos e científicos procuram explicar, a arte tem a função de nos inquietar. Por isso, recorreremos a um ficcionista para problematizar a univocidade no par verticalidade vs. horizontalidade. Em geral, temos a primeira como positividade: aprumar-se, ereto, de pé; a segunda como negatividade: prostrar-se, cabisbaixo, caído. Mas, João Guimarães Rosa, no conto "Conversa de bois", do livro Sagarana (1967/1946), mais do que trazer culturas humanas diversas, recorre aos animais para colocar sob suspeição a inevitabilidade de nossos corredores isotópicos. Dizem eles entre si, ao puxarem um carro-de-boi:

O homem é um bicho esmochado, que não devia haver. Nem convém espiar muito para o homem. É o único vulto que faz ficar zonzo, de se olhar muito. É comprido demais, para cima, e não cabe todo de uma vez, dentro dos olhos da gente. (...). Os bois soltos não pensam como o homem. Só nós, bois-de-carro, sabemos pensar como o homem! (...). Não podemos mais deixar de pensar como o homem. Estamos todos pensando como o homem pensa. (Rosa, 1967/1946, pp. 288-291)

Mestre Rosa produz, por meio da conversa entre os bois, o difícil estranhamento daquilo que nos é familiar, tornando o homem um bicho muito esquisito, um varapau que incomoda, pois não cabe no campo visual de outros bichos. Ressalta também o papel limitador, domesticador, da inserção em uma dada cultura. Ele diferencia as percepções dos bois soltos e dos bois-de-carro, como diferenciamos as das culturas ditas primitivas e das consideradas civilizadas.

Interessam-nos, aqui, especialmente, as metáforas fundamentais ou conceituais, pois elas têm um forte poder cognitivo, estruturando uma percepção global e subordinando todo um conjunto de 
metáforas secundárias que lhes são associadas. Metáforas mais básicas, orientacionais e ontológicas, compõem metáforas complexas como as conceituais. Lakoff e Johnson dão como exemplo de metáfora conceptual discussão é guerra. A partir dela, podemos perceber a dimensão bélica de afirmações que fazemos no dia-a-dia, sem ter essa intenção explícita: ganhar o debate, derrotar os argumentos, ponto de vista indefensável. Lembramos que uma frase tão corriqueira na narração de um jogo de futebol pode ser iluminada igualmente em metáforas bélicas que nos passam desapercebidas, desde que tenhamos em mente a metáfora conceptual jogo é uma guerra: "o artilheiro do time, ao bater um tiro livre direto, mandou uma bomba para o gol adversário".

Retomando Perelman, vamos trazer outra metáfora fundamental sobre o conhecimento (além da luz, já referida) - e, por extensão, da educação - que ele apresenta, destacando suas variações. Trata-se da metáfora do caminho que perpassa diversas correntes filosófica, ao longo de séculos. O método para adquirir conhecimentos é comparado a um percurso. Também aqui, temos uma profusão de variantes, que evidenciam (e ocultam) aspectos de acordo com os interesses do autor. Assim, Descartes concebe o caminhar solitário, como uma atividade individual. Leibniz, por seu turno, enfatiza a dimensão social do conhecimento, adotando a metáfora de um caminhar coletivo. Já para Hegel o conhecimento é um caminho que - assim como o espírito absoluto - se constrói a si mesmo. E o próprio Perelman dá sua contribuição a esse extenso material metafórico lembrando que há caminhos que quase se desfizeram pelo esquecimento, ficando cobertos pela vegetação. Mas acentua que podemos retomá-los e alargá-los. Podemos imaginar que ele tinha em mente a revitalização da retórica, de que foi um dos principais artífices.

Além da metáfora do caminho, outras se prestam ao papel de fundamentais ou conceituais da educação e do ensino. Mais uma vez, vamos partir da linguagem cotidiana, de metáforas adormecidas, para despertá-las e buscar as ideias que lhes subjazem. É comum alguém responder, diante da indagação acerca de que turma seu filho frequenta na Educação Infantil, que ele está no jardim. Tal resposta não causa estranhamento pois entende-se que se trata da turma Jardim da Infância. Não se imagina que a criança passe os dias, na escola, em um gramado. Mas, Jardim da Infância é um tropo que está atrelado a uma importante metáfora conceptual da história da educação; o ensino como cultivo. A analogia que a metáfora condensa é: o professor está para o aluno, assim como o jardineiro para a planta. Daí decorrem inúmeras possibilidades de desenvolvimento elaboradas por diversas correntes pedagógicas. Comênio, por exemplo, a utiliza amiúde, ao longo da Didática Magna (1995). Sua força provém da premissa a que o leitor deve aderir: se na natureza é assim, na escola também deve ser.

Mas, talvez, a metáfora conceptual de maior recorrência na história da educação seja a do ensino como preenchimento do aluno. As metáforas ontológicas que lhe servem de base são evidentes: as ideias são coisas e a mente é um recipiente. Fazendo a ponte entre elas, temos uma terceira - a do canal que transfere as coisas (a matéria escolar) para os recipientes (os alunos). Por isso, uma afirmativa muito comum quanto ao ensino é o professor se referir a passar conteúdos para a turma. Uma imagem clássica do preenchimento é o professor como a jarra d'água e o aluno como o copo (vazio) a ser preenchido.

Vamos analisar, agora, uma variante de metáfora conceptual do ensino como transferência de conteúdo, preenchimento. Uma versão adequada ao contexto da modernidade, após a invenção da imprensa, é a analogia desenvolvida no penúltimo capítulo da Didática Magna (1995/1649), da sala de aula como uma tipografia. Vamos abrir um espaço maior a ela, pois servirá de contraponto a metáforas conceituais da tecnologia educacional da contemporaneidade, que serão o objeto central de nossa análise. Comênio arrola, inicialmente, os elementos da tipografia e seus correspondentes no processo pedagógico: 
...O papel são os alunos, em cujos espíritos devem ser impressos os caracteres das ciências. Os tipos são os livros didáticos e todos os outros instrumentos propositadamente preparados para que, com a sua ajuda, as coisas a aprender se imprimam nas mentes com pouca fadiga. A tinta é a viva voz do professor que transfere o significado das coisas, dos livros para as mentes dos alunos. O prelo é a disciplina escolar que a todos dispõe e impele para se embebedarem dos ensinamentos. (p. 458)

Transborda o entusiasmo de Comênio diante das possibilidades oferecidas à educação com a invenção da imprensa. E não era para menos. Basta lembrar que um importante historiador da leitura e de livro, Alberto Manguel, estima que tão somente 30 anos após a invenção de Gutenberg tenham sido produzidos mais livros impressos do que os manuscritos até então. Mas seu entusiasmo pelas possibilidades abertas pela nova tecnologia não eclipsou o papel do docente, acentuando a importância de sua atuação. Ou seja, não sucumbiu ao que poderíamos chamar de fetiche da tecnologia, como se esta pudesse garantir o bom resultado da mediação docente ... o tipógrafo serve-se de um compenedor para dispor linearmente os caracteres em palavras, as palavras em linhas, as linhas em colunas, para que nada fique fora de proporção. Do mesmo modo, aos educadores da juventude, é necessário dar normas, em conformidade com as quais executem as suas obras, isto é, devem escrever-se para uso deles Livros-roteiros que os aconselhem quanto ao que hão-de fazer, em que lugar e de que modo, para que não se caia em erro. Os livros didácticos serão, portanto, de dois gêneros: verdadeiros livros de texto para os alunos, e livros-roteiro (informatorii) para os professores, para que aprendam a servir-se bem daqueles. Dissemos que a tinta didáctica é a voz do professor. Efectivamente, assim como os caracteres, quando estão enxutos, permanecem também (pela acção do prelo) impressos no papel, mas não deixam, todavia, senão vestígios cegos, que, pouco depois, desaparecem, mas, embebidos de tinta, nele imprimem imagens visibilíssimas e quase indeléveis, assim também as coisas que os mudos professores das crianças, os livros de texto, colocam diante delas, são realmente mudas, obscuras e imperfeitas, mas, quando aos livros se junta a vOz do professor (que explica tudo racionalmente, segundo a capacidade dos alunos, e tudo ensina a pôr em prática), tornam-se cheios de vida, imprimem-se profundamente nos seus espíritos, e assim, finalmente, os alunos entendem verdadeiramente aquilo que aprendem. (p. 460) (...) embebem-se de tinta os tipos metálicos, para que a sua imagem fique claramente impressa no papel. Também o professor ilustrará sempre com a própria voz a lição que dá em determinada hora, lendo-a, relendo-a e explicando-a, de modo a poder entender-se tudo claramente. (p. 464)

Como já enfatizamos, a escolha de uma metáfora ou analogia põe em destaque certos aspectos da similitude e deixa outros obscurecidos. Dissemos também que a argumentação por meio desses tropos expõe uma instabilidade, como em qualquer argumentação, pois não se trata de uma demonstração dentro de um sistema plenamente formalizado, onde as inferências são necessárias. Assim é que podemos desenvolver a analogia da tipografia ressaltando a concepção do aluno como uma folha em branco. É como o copo vazio a ser preenchido. Em contrapartida, poderíamos conceber o aluno como uma folha que porta um texto (seus saberes prévios) com a qual o saber do professor buscará produzir um intertexto. 
Em sentido oposto, toda uma tradição pedagógica, desde Rousseau, passando pelo escolanovismo e Paulo Freire (1992), com a metáfora crítica da concepção bancária da educação vai se contrapor à prática educacional de depósito de informações, sem estimular os educandos a se autorizarem a construir, coletivamente, sua visão de mundo. As pedagogias bancárias têm em comum uma concepção de transmissão, impressão ou depósito, sempre de mão única, dos que sabem (são plenos) para os que não sabem (os vazios). Esses exemplos mostram a importância, para o entendimento de um material analógico ou metafórico tão vasto, de se ter em mente as figuras anteriores com que se dialoga. Por isso, para Jorge Luis Borges (1999, p. 12), a história universal poderia ser entendida como a história da recorrência de algumas metáforas.

Acreditamos poder, enfim, mergulhar no exame da metáfora da tecnologia educacional como ferramenta.

\section{Tecnologias Educacionais como Ferramentas}

De modo geral, ferramentas são usualmente concebidas como objetos que possibilitam, apoiam ou facilitam a realização de determinadas tarefas. O martelo e a chave de fenda são dois exemplos cotidianos de ferramentas assim compreendidas. Ambos são artefatos que têm propósitos próprios, refletidos em projetos de design específicos e concretizados em materialidades específicas formas, materiais e dimensões particularizadas às tarefas nas quais se imagina que serão utilizadas. Adaptam-se a essas tarefas, e adaptam-se às mãos de quem as irá conduzir. Prestam-se a sustentar atividades de manutenção, construção e de criação de novos objetos, da montagem da mobília contemporânea produzida em massa à arte da escultura na pedra. Ferramentas, nessa concepção, constituem-se em suporte a ações necessárias à resolução de problemas de ordem prática, também em processos potencialmente mais criativos. Nesse sentido, ferramentas podem ser pensadas como próteses ou "extensões, projeções, amplificações do ser humano, do próprio corpo humano, em suas diversas especificações (os sentidos, os membros, o sistema nervoso, etc.).” (Ferraz, 2000, p. 117)

No contexto da tecnologia educacional, muitos são os artefatos e rótulos defendidos como ferramentas: de ambientes pessoais de aprendizagem a Big Data e Learning Analytics, passando por aplicativos variados, ambientes virtuais (e pessoais) de aprendizagem e o próprio computador. Desse modo, dissemina-se uma imagem das tecnologias como simples suporte ou apoio a ações envolvidas na educação, sobretudo no processo de ensino e aprendizagem. Em particular, entra em jogo a ideia de que tais tecnologias promovem formas mais eficientes de conduzir ações previamente realizadas de outras maneiras. Com o uso de ferramentas, otimiza-se a realização de tarefas.

O cenário, porém, é mais complexo. Relatos de usos de artefatos digitais em contextos educacionais tendem a apresentar, com bastante frequência, "mais do mesmo", ou seja, a mera substituição de meios: como as ferramentas de metal fundido substituíram as ferramentas de madeira utilizadas durante séculos, a planilha eletrônica substituiu a impressa, o processador de texto tornou obsoleta a velha máquina de escrever, os slides em PowerPoint substituíram as anotações no quadronegro e os aplicativos CAD (Computer Assisted Design) tomaram o lugar do equipamento tradicional utilizado para compor o desenho técnico no papel. Isso reflete a enorme pressão, que ecoa, também, no próprio PNE 2014-2024, no sentido de se promover a inovação, compreendida como a inserção de novas tecnologias, sobretudo, digitais, em contextos de práticas tradicionais, em geral a partir da premissa ingênua de que a simples substituição de suportes será suficiente para engendrar mudanças mais profundas.

A metáfora da tecnologia como ferramenta, assim, como qualquer outra metáfora, tende a privilegiar alguns aspectos do tema, enquanto obscurece outros, contribuindo e reforçando 
perspectivas que informam, de maneiras específicas, a formulação e a resolução de problemas, bem como a tomada de decisões. Ao encorajar que se focalizem objetos de forma destacada de sua origem, a metáfora em questão oculta aspectos contextuais, relativos aos espaços, tempos e atores envolvidos tanto na produção de artefatos, quanto em seus usos na educação. No entanto, como os exemplos mundanos acima sugerem, ferramentas tendem a ser projetadas e construídas de forma consistente com os propósitos de uso aos quais se destinam. Ferramentas têm um para quêe - inicial ou provisório, que seja.

Nesse sentido, por exemplo, com exceção dos computadores pioneiros, criados especificamente para tornar mais eficiente a tarefa de completar grandes quantidades de cálculos, computadores não se prestam a um conjunto limitado de tarefas determinadas por projeto. Para o usuário do computador pessoal moderno, o computador estaria mais próximo de uma caixa preta, concebida na engenharia como um módulo pronto e fechado, cuja estrutura e funcionamento não se precisa conhecer - basta apenas saber qual a relação entre sua entrada e sua saída, ou seja, sua função, para que se possa integrá-lo em um todo mais complexo. O computador tem um caráter generalista; em particular, não incorpora especificidades de natureza educacional em sua construção, o que vai de encontro à sua concepção como ferramenta educacional.

O projeto original do hardware do computador não carece de requisitos, é claro, mas a máquina utilizável pelo humano decorre da integração, ao hardware, de software, cuja produção opera em níveis de abstração mais altos e relativamente independentes dos detalhes do hardware. Dessa forma, parece tratar-se, de fato, de um artefato em processo de construção continuada a partir da integração de novos softwares. Uma vez que grande parte dos artefatos da tecnologia educacional defendidos como ferramentas são, basicamente, produtos da engenharia de software - plataformas de ensino-aprendizagem, games, softwares (especificamente) ditos educacionais - a noção de que software seria mera ferramenta também obscurece questões profundas e complexas, uma vez que software, como qualquer outro artefato, não é um produto apolítico, pois, além dos efeitos que produz no mundo, é produzido por meio de trabalho social e material (Kitchin, 2017).

Assim, a metáfora da tecnologia educacional como ferramenta parece ofuscar questionamentos de cunho sociopolítico, incluindo, sobretudo, a premissa de que as tarefas a serem executadas com (ou por) as tecnologias educacionais estão não apenas bem definidas, mas, crucialmente, bem compreendidas e representadas no contexto de produção desses artefatos. Ocultam-se, aqui, questões relativas a perspectivas acerca da educação e dos processos de ensino e aprendizagem. Os discursos de marketing da indústria da tecnologia educacional são fonte inesgotável de slogans baseados em termos e expressões da educação (por exemplo, construtivismo), mas é duvidoso que haja entendimento geral da complexidade desses processos, bem como compreensão aprofundada de teorias e conceitos pertinentes.

Por outro lado, mesmo artefatos projetados e construídos para fins específicos oferecem possibilidades de usos alternativos aos seus propósitos originais de design. Qualquer artefato tem possibilidades de usos não planejados por quem as idealizou originalmente: utilizações inesperadas concretizam-se em apropriações criativas, oportunistas ou fortuitas. Assim, os exemplos qualificados acima como mundanos são essenciais a tarefas de construção (de móveis, por exemplo), mas podem ser úteis de formas inusitadas (por exemplo, uma chave de fenda pode ser usada para abrir uma lata de tinta). Mais ainda: essas mesmas ferramentas podem ser utilizadas de formas destrutivas e, até mesmo, violentas.

As tarefas que podem ser realizadas com ferramentas, portanto, não são restritas, mas são limitadas. As armas de fogo, um exemplo talvez extremo, porém, interessante, são especificamente projetadas e construídas para maior eficiência naquilo a que são destinadas; assim, é difícil sustentar o slogan "armas não matam pessoas; pessoas matam pessoas", pois é difícil encontrar usos alternativos para elas. Isso ilustra a profunda relação entre a produção e as possibilidades de uso de 
artefatos tecnológicos, articulada sucintamente por Feenberg (2005, p. 115, tradução nossa): “a tecnologia [...] não é neutra, mas, sim, favorece alguns fins específicos e obstrui outros". Em outras palavras, a tecnologia é profundamente ideológica (Selwyn, 2014), e a metáfora da tecnologia educacional como ferramenta apoia uma visão instrumental, funcionalista e reducionista dos processos envolvidos na criação e uso de artefatos.

Posicionada em um contexto mais abrangente, a metáfora se revela consistente com os papéis destinados às tecnologias educacionais no contexto geral de uma educação retratada como anacrônica - que precisa de atualização - quebrada (broken) - que precisa de conserto - falida - que precisa de investimento e reconstrução, enfim, de um setor que precisa de transformação, quiçá radical - uma revolução inevitável, de fato, já em curso a partir da defesa de uma base de tecnologias ditas "disruptivas" (neologismo gerado por uma tradução literal do termo em inglês disruption). Tais discursos baseiam-se em premissas tacitamente consensuais, um conjunto de pressupostos implícitos, mas amplamente compartilhados sem sequer serem discutidos: a educação está quebrada agora ou sempre esteve? É possível uma educação plena, total, integral, como defendem tais discursos? E a precarização da formação e da profissão docente, inclusive as "tutorias"? E o número de alunos por professor ou tutor: não seria, talvez, bem mais eficaz ter-se menos alunos em sala? Nada disso é problematizado. Trata-se de uma construção discursiva perversa que parte de premissas implícitas: sabe-se que...

Nesse contexto, caracterizado pelo uso de linguagem exagerada, alarmista e, por vezes, cataclísmica, em alusões a tsunamis, terremotos e avalanches, por exemplo, tecnologias educacionais são soluções para problemas, pois constituem-se em ferramentas de apoio ao trabalho de reparar o que está quebrado ou ao desafio de criar algo novo em substituição ao que está ultrapassado. Enquanto são apresentadas como ferramentas que apoiam o ensino e a aprendizagem, em alguns casos mais extremos, são retratadas como alternativas para substituir a ação docente: o próprio professor é transformado em peça defeituosa ou obsoleta de um sistema mecanizado no qual, efetivando-se o "deslocamento radical" analisado por Barreto (2017), objetos tornam-se sujeitos.

Dessa forma, a metáfora promove a naturalização do solucionismo tecnológico duramente criticado por Morozov (2013): a ideia da tecnologia como solução de problemas, de fato, mal formulados, configurando, na prática, situações de soluçoes em busca de problemas. Enquanto as tecnologias digitais tendem a ser tratadas com uma "intensidade quase religiosa" (Selwyn, 2014, posição 1034), novas soluções técnicas são, às vezes, propostas ou postas em prática a partir do argumento simplista de "que as tecnologias deveriam ser usadas na educação porque isso é possível, ou porque uma dita tecnologia existe" (Selwyn, 2017, p. 92). Crucialmente, essas tecnologias não existem em um vácuo político e econômico: são produtos de uma indústria em plena expansão e que envolve múltiplos stakeholders (partes interessadas), dentre os quais destacam-se grandes editoras e vastos conglomerados educacionais multinacionais, além da indústria da tecnologia e instituições filantrópicas a ela associadas.

\section{Considerações Finais}

Conforme argumentou Selwyn (2016, p. 107), a tecnologia digital tornou-se "uma 'boa' maneira de expandir os interesses de negócios e do comércio na educação", e a metáfora da tecnologia educacional como ferramenta parece instrumental nesse processo de expansão. Este artigo discutiu implicações dessa concepção como uma metáfora conceptual, ou seja, como uma metáfora que estabelece formas de perceber, pensar e relacionar-se com o mundo, e, assim, estrutura o pensamento e a ação. Conforme sugerido, uma vez que parece promover uma concepção da tecnologia como neutra, promove, também, uma perspectiva reducionista da relação entre o humano 
e o técnico. Em particular, tecnologias como ferramentas tendem a ser apresentadas em contraposição a caricaturas empobrecidas e, com frequência, desvinculadas da realidade dos processos educacionais. Certamente não é uma coincidência que os discursos de marketing de tecnologias digitais para a educação, sobretudo, ofereçam seus produtos como soluções de problemas apontados a partir de descrições caricatas do trabalho docente, da escola e da relação entre professor e aluno.

A apropriação, em contextos educacionais, de tecnologias desenvolvidas, sobretudo a partir do final da década de 1940, tem aberto novos horizontes conceituais encapsulados em um conjunto de novas metáforas que priorizam objetos em detrimento de pessoas. Imaginando que "talvez a história universal seja a história de algumas metáforas", como sugere Borges (1999, p. 12), a sala de aula como tipografia, a metáfora de Comênio examinada acima, reflete um contexto marcado por um tipo específico de tecnologia, e poderia ser incluída em uma perspectiva histórica da relação entre a educação e a tecnologia a partir de suas metáforas. De todo modo, a metáfora do autor da Didáctica Magna não exclui os agentes humanos centrais ao processo educacional: professor e aluno. A metáfora da tecnologia como ferramenta, por outro lado, é consistente com metáforas mais atuais, tais como as peças Lego e puzそle, que, especificamente, dão forte destaque aos materiais e recursos didáticos, também, ocasionalmente, descritos como ferramentas e, em geral, concebidos como objetos padronizados e neutros (Lemgruber \& Ferreira, 2018).

Ainda que a palavra ferramenta não apareça no texto do PNE 2014-2024, o documento parece pautado em uma ideia que precisa de escrutínio. A discussão apresentada neste artigo reitera a necessidade de se abordar a tecnologia de forma crítica, trazendo à tona questões fundamentais relativas à multiplicidade de contextos de produção e consumo de artefatos produzidos visando para quês amiúde escusos à ideia de uma formação humana mais abrangente.

\section{Referências}

Barreto, R. (2017). Objetos como sujeitos: O deslocamento radical. In G. M. S. Ferreira, L. A. S. Rosado, \& J. S Carvalho (Orgs.) Educação e tecnologia: Abordagens críticas (pp. 124-141). Rio de Janeiro: Editora UNESA. Disponível em: < https://bit.ly/2nOEwuD>. Acesso em: 17 jul. 2018.

Black, M. (1966). Modelos y Metáforas. Madrid: Estructura y Función.

Borges, J. L. (1999). Obras Completas. Vol. II. São Paulo, Globo.

Brasil. (2014). Lei no 13.005, de 25 de junho de 2014. Aprova o Plano Nacional de Educação.

Brasília: Diário Oficial da União, Edição Extra de 26/6/2014, Seção 1, Página 1.

Disponível em: <https://bit.ly/1LRh3gh>. Acesso em: 17 jul. 2018.

Comênio, J. A. (1995). Didáctica Magna. Lisboa: Calouste Golbeinken.

Eco, U. (2017). Pape Satàn Aleppe: Crônicas de uma sociedade líquida. Rio de Janeiro: Record.

Feenberg, A. (2005). Teoría crítica de la tecnología. Revista CTS, 5(2), 109-123.

Ferraz, M. C. F. (2000). Sociedade tecnológica: De Prometeu a Fausto. Contracampo, 4, 177-124. doi: 10.22409/contracampo.v0i04.420.

Freire, P. (1992). Pedagogia do Oprimido. Rio de Janeiro: Paz e Terra.

Kitchin, R. (2017). Thinking critically about and researching algorithms. Information, Communication and Society, 20(1), 14-29. doi: 10.1080/1369118X.2016.1154087.

Lakoff, G., \& Johnson, M. (2002). Metáforas da vida cotidiana. São Paulo: EDUC e Mercado das Letras.

Lemgruber, M. S., \& Ferreira, G. M. S. (2018) Metáforas fundamentais da tecnologia educacional. Educação em Foco, 23(1), 15-38. doi: 10.22195/2447-5246v23n120183351. 
Montaigne, M. de. (1996) Ensaios. Vol. 1. Coleção Os Pensadores. São Paulo: Editora Nova Cultural.

Morozov, E. (2013). To save everything, click here. The folly of technological solutionism. Nova Iorque: Public Affairs.

Perelman, C. (1987). Analogia e Metáfora. In: Enciclopédia Einaudi vol. 11 (pp. 207-217). Lisboa: Imprensa Nacional/Casa da Moeda.

Perelman, C. (1997). Retóricas. São Paulo: Martins Fontes.

Perelman, C. (1999). O império retórico. Porto: Edições ASA.

Perelman, C., \& Olbrechts-Tyteca, L. (1996) Tratado da Argumentação - a nova retórica. São Paulo: Editora Martins Fontes.

Rabelais, F. (2009). Gargântua e Pantagruel. Belo Horizonte: Editora Itatiaia.

Rosa, J. G. (1967/1946). Sagarana. Rio de Janeiro: Livraria José Olympio Editora.

Rosado, L. A. S., Ferreira, G. M. S., \& Carvalho, J. S. (2017). Educação e tecnologia na literatura acadêmica on-line em português. In G. M. S. Ferreira, L. A. S. Rosado, \& J. S Carvalho (Orgs.) Educação e tecnologia: Abordagens críticas (pp. 208-254). Rio de Janeiro: Editora UNESA. Disponível em: <https://bit.ly/2nOEwuD>. Acesso em: 17 jul. 2018.

Selwyn, N. (2014). Distrusting Educational Technology. Londres: Routledge.

Selwyn, N. (2015). Minding our language: Why education and technology is full of bullshit... and what can be done about it. Learning, Media and Technology [Editorial], 40(2), 1-7.

Selwyn, N. (2016). Is Technology Good for Education? Cambridge: Polity Press.

Selwyn, N. (2017). Educação e Tecnologia: questões críticas. In G. M. S. Ferreira, L. A. S. Rosado, \& J. S Carvalho, (Org.) Educação e tecnologia: Abordagens críticas (pp. 85-102). Rio de Janeiro: Editora UNESA. Disponível em: < https://bit.ly/2nOEwuD>. Acesso em: 17 jul. 2018. 


\section{Sobre o Autores}

Giselle Martins dos Santos Ferreira

PUC-Rio

gmdsferreira@gmail.com

http:/ / orcid.org/0000-0002-8498-5390

Professora Adjunta no Departamento de Educação da PUC-Rio. Professora Adjunta no PPGE/UNESA (2011-2018), onde atuou como Coordenadora de Linha (2012-2017) e Líder do Grupo de Pesquisas TICPE (2012-2018) (http://ticpe.wordpress.com). Professora-Pesquisadora na Open University do Reino Unido (1998-2012), onde também atuou como Pesquisadora Associada (2012-2016).

\section{Márcio Silveira Lemgruber}

PPGE/UNESA

mslemgruber@gmail.com

https://orcid.org/0000-0001-9269-5695

Professor Adjunto no PPGE/UNESA (2012-presente). Professor Aposentado da UFJF.

Membro do Grupo de Pesquisas TICPE (http://ticpe.wordpress.com).

\section{Sobre o Editores}

\section{Lílian do Valle}

Universidade do Estado do Rio de Janeiro (UERJ)

lilidovalle@gmail.com

https://orcid.org/0000-0002-8694-9297

Professora titular de Filosofia da Educação da Universidade do Estado do Rio de Janeiro, doutora em Educação pela Universidade de Paris V - René Descartes.

\section{Daniel Mill}

Universidade Federal de São Carlos (UFSCar)

mill.ufscar@gmail.com

https://orcid.org/0000-0002-8336-3645

Professor do Programa de Pós-Graduação em Educação da Universidade Federal de São Carlos (UFSCar). Doutor em Educação (UFMG). Gestor em Educação a Distância.

\section{Aldo Victorio Filho}

Universidade do Estado do Rio de Janeiro (UERJ)

avictorio@gmail.com

https://orcid.org/0000-0002-7132-8615

Professor do Programa de Pós-Graduação em Artes da Universidade do Estado (PPGArtes).

Doutor em Educação (UERJ). 


\section{arquivos analíticos de políticas educativas}

Volume 26 Número 112

17 de setembro 2018

ISSN 1068-2341

(C)

O Copyright e retido pelo/a o autor/a (ou primeiro co-autor) que outorga o direito da primeira publicação à revista Arquivos Analíticos de Políticas Educativas. Más informação da licença de Creative Commons encontram-se em http://creativecommons.org/licenses/by-nc-nd/2.5. Qualquer outro uso deve ser aprovado em conjunto pelo/s autor/es e por AAPE/EPAA. AAPE/EPAA é publicada por Mary Lou Fulton Institute Teachers College da Arizona State University. Os textos publicados em AAPE são indexados por CIRC (Clasificación Integrada de Revistas Científicas, Espanha) DIALNET (Espanha),Directory of Open Access Journals, Education Full Text (H.W. Wilson), EBSCO Education Research Complete, ERIC, QUALIS A1 (Brasil), SCImago Journal Rank; SCOPUS, SOCOLAR (China).

Curta a nossa comunidade EPAA's Facebook https://www.facebook.com/EPAAAAPE e Twitter feed@epaa_aape. 


\section{arquivos analíticos de políticas educativas conselho editorial}

Editor Consultor: Gustavo E. Fischman (Arizona State University)

Editoras Associadas: Kaizo Iwakami Beltrao, (Brazilian School of Public and Private Management - EBAPE/FGV, Brazil), Geovana Mendonça Lunardi Mendes (Universidade do Estado de Santa Catarina), Gilberto José Miranda, (Universidade Federal de Uberlândia, Brazil), Marcia Pletsch, Sandra Regina Sales (Universidade Federal Rural do Rio de Janeiro)

\begin{tabular}{|c|c|c|}
\hline Almerindo Afonso & Alexandre Fernandez Vaz & José Augusto Pacheco \\
\hline Universidade do Minho & Universidade Federal de Santa & Universidade do Minho, Portugal \\
\hline Portugal & Catarina, Brasil & \\
\hline Rosanna Maria Barros Sá & Regina Célia Linhares Hostins & Jane Paiva \\
\hline $\begin{array}{l}\text { Universidade do Algarve } \\
\text { Portugal }\end{array}$ & $\begin{array}{l}\text { Universidade do Vale do Itajaí, } \\
\text { Brasil }\end{array}$ & $\begin{array}{l}\text { Universidade do Estado do Rio de } \\
\text { Janeiro, Brasil }\end{array}$ \\
\hline Maria Helena Bonilla & Alfredo Macedo Gomes & Paulo Alberto Santos Vieira \\
\hline Universidade Federal da Bahia & Universidade Federal de Pernambuco & Universidade do Estado de Mato \\
\hline Brasil & Brasil & Grosso, Brasil \\
\hline Rosa Maria Bueno Fischer & Jefferson Mainardes & Fabiany de Cássia Tavares Silva \\
\hline $\begin{array}{l}\text { Universidade Federal do Rio Grande } \\
\text { do Sul, Brasil }\end{array}$ & $\begin{array}{l}\text { Universidade Estadual de Ponta } \\
\text { Grossa, Brasil }\end{array}$ & $\begin{array}{l}\text { Universidade Federal do Mato } \\
\text { Grosso do Sul, Brasil }\end{array}$ \\
\hline Alice Casimiro Lopes & Jader Janer Moreira Lopes & António Teodoro \\
\hline $\begin{array}{l}\text { Universidade do Estado do Rio de } \\
\text { Janeiro, Brasil }\end{array}$ & $\begin{array}{l}\text { Universidade Federal Fluminense e } \\
\text { Universidade Federal de Juiz de Fora, } \\
\text { Brasil }\end{array}$ & $\begin{array}{l}\text { Universidade Lusófona } \\
\text { Portugal }\end{array}$ \\
\hline $\begin{array}{l}\text { Suzana Feldens Schwertner } \\
\text { Centro Universitário Univates } \\
\text { Brasil }\end{array}$ & $\begin{array}{l}\text { Debora Nunes } \\
\text { Universidade Federal do Rio Grande } \\
\text { do Norte, Brasil }\end{array}$ & $\begin{array}{l}\text { Lílian do Valle } \\
\text { Universidade do Estado do Rio de } \\
\text { Janeiro, Brasil }\end{array}$ \\
\hline $\begin{array}{l}\text { Flávia Miller Naethe Motta } \\
\text { Universidade Federal Rural do Rio de } \\
\text { Janeiro, Brasil }\end{array}$ & $\begin{array}{l}\text { Alda Junqueira Marin } \\
\text { Pontifícia Universidade Católica de } \\
\text { São Paulo, Brasil }\end{array}$ & $\begin{array}{l}\text { Alfredo Veiga-Neto } \\
\text { Universidade Federal do Rio Grande } \\
\text { do Sul, Brasil }\end{array}$ \\
\hline & $\begin{array}{l}\text { Dalila Andrade Oliveira } \\
\text { Universidade Federal de Minas } \\
\text { Gerais, Brasil }\end{array}$ & \\
\hline
\end{tabular}




\section{archivos analíticos de políticas educativas consejo editorial}

Editor Consultor: Gustavo E. Fischman (Arizona State University)

Editores Asociados: Armando Alcántara Santuario (Universidad Nacional Autónoma de México), Jason Beech (Universidad de San Andrés), Angelica Buendia (Metropolitan Autonomous University), Ezequiel Gomez Caride (Pontificia Universidad Católica Argentina), Antonio Luzon (Universidad de Granada), José Luis Ramírez Romero (Universidad Autónoma de Sonora, México), Paula Razquin (Universidad de San Andrés)

Claudio Almonacid

Universidad Metropolitana de

Ciencias de la Educación, Chile

\section{Miguel Ángel Arias Ortega}

Universidad Autónoma de la

Ciudad de México

Xavier Besalú Costa

Universitat de Girona, España

Xavier Bonal Sarro Universidad

Autónoma de Barcelona, España

Antonio Bolívar Boitia

Universidad de Granada, España

José Joaquín Brunner Universidad Diego Portales, Chile

Damián Canales Sánchez

Instituto Nacional para la

Evaluación de la Educación,

México

Gabriela de la Cruz Flores

Universidad Nacional Autónoma de México

Marco Antonio Delgado Fuentes

Universidad Iberoamericana,

México

Inés Dussel, DIE-CINVESTAV, México

Pedro Flores Crespo Universidad

Iberoamericana, México
Ana María García de Fanelli

Centro de Estudios de Estado y

Sociedad (CEDES) CONICET,

Argentina

Juan Carlos González Faraco

Universidad de Huelva, España

María Clemente Linuesa

Universidad de Salamanca, España

Jaume Martínez Bonafé

Universitat de València, España

\section{Alejandro Márquez Jiménez}

Instituto de Investigaciones sobre la Universidad y la Educación, UNAM, México

María Guadalupe Olivier Tellez, Universidad Pedagógica Nacional, México

Miguel Pereyra Universidad de

Granada, España

Mónica Pini Universidad Nacional de San Martín, Argentina

Omar Orlando Pulido Chaves Instituto para la Investigación

Educativa y el Desarrollo

Pedagógico (IDEP)

José Ignacio Rivas Flores

Universidad de Málaga, España

\section{Miriam Rodríguez Vargas}

Universidad Autónoma de

Tamaulipas, México

José Gregorio Rodríguez

Universidad Nacional de Colombia, Colombia

Mario Rueda Beltrán Instituto de Investigaciones sobre la Universidad y la Educación, UNAM, México

José Luis San Fabián Maroto

Universidad de Oviedo, España

Jurjo Torres Santomé, Universidad de la Coruña, España

Yengny Marisol Silva Laya

Universidad Iberoamericana, México

Ernesto Treviño Ronzón

Universidad Veracruzana, México

\section{Ernesto Treviño Villarreal}

Universidad Diego Portales

Santiago, Chile

Antoni Verger Planells

Universidad Autónoma de

Barcelona, España

Catalina Wainerman

Universidad de San Andrés, Argentina

Juan Carlos Yáñez Velazco

Universidad de Colima, México 


\section{education policy analysis archives editorial board}

Lead Editor: Audrey Amrein-Beardsley (Arizona State University)

Executive Editor: Gustavo E. Fischman (Arizona State University)

Associate Editors: David Carlson, Lauren Harris, Eugene Judson, Mirka Koro-Ljungberg, Scott Marley, Molly Ott, Iveta Silova (Arizona State University)

Cristina Alfaro San Diego State University

Gary Anderson New York University

Michael W. Apple University of Wisconsin, Madison

Jeff Bale OISE, University of Toronto, Canada

Aaron Bevanot SUNY Albany

David C. Berliner Arizona

State University

Henry Braun Boston College

Casey Cobb University of

Connecticut

Arnold Danzig San Jose State University

Linda Darling-Hammond

Stanford University

Elizabeth H. DeBray University of Georgia

Chad d'Entremont Rennie Center for Education Research \& Policy

John Diamond University of Wisconsin, Madison

Matthew Di Carlo Albert Shanker Institute

Sherman Dorn

Arizona State University

Michael J. Dumas University of California, Berkeley

Kathy Escamilla University of Colorado, Boulder

Yariv Feniger Ben-Gurion

University of the Negev, Israel

Melissa Lynn Freeman Adams State College

Rachael Gabriel

University of Connecticut
Amy Garrett Dikkers University

of North Carolina, Wilmington

Gene V Glass Arizona

State University

Ronald Glass University of California, Santa Cruz

Jacob P. K. Gross University of Louisville

Eric M. Haas WestEd

Julian Vasquez Heilig California

State University, Sacramento

Kimberly Kappler Hewitt University

of North Carolina Greensboro

Aimee Howley Ohio University

Steve Klees University of Maryland Jaekyung Lee SUNY Buffalo

Jessica Nina Lester

Indiana University

Amanda E. Lewis University of Illinois, Chicago

Chad R. Lochmiller Indiana

University

Christopher Lubienski Indiana

University

Sarah Lubienski Indiana University

William J. Mathis University of

Colorado, Boulder

Michele S. Moses University of Colorado, Boulder

Julianne Moss Deakin

University, Australia

Sharon Nichols University of Texas, San Antonio

Eric Parsons University of Missouri-Columbia

Amanda U. Potterton

University of Kentucky
Susan L. Robertson Bristol

University, UK

Gloria M. Rodriguez

University of California, Davis

R. Anthony Rolle University of Houston

A. G. Rud Washington State University

Patricia Sánchez University of University of Texas, San Antonio

Janelle Scott University of California, Berkeley

Jack Schneider University of

Massachusetts Lowell

Noah Sobe Loyola University

Nelly P. Stromquist University of Maryland

Benjamin Superfine University of Illinois, Chicago

Adai Tefera Virginia

Commonwealth University

Tina Trujillo University of California, Berkeley

Federico R. Waitoller University of Illinois, Chicago

Larisa Warhol

University of Connecticut

John Weathers University of

Colorado, Colorado Springs

Kevin Welner University of Colorado, Boulder

Terrence G. Wiley Center for Applied Linguistics

John Willinsky

Stanford University

Jennifer R. Wolgemuth University of South Florida

Kyo Yamashiro Claremont Graduate University 